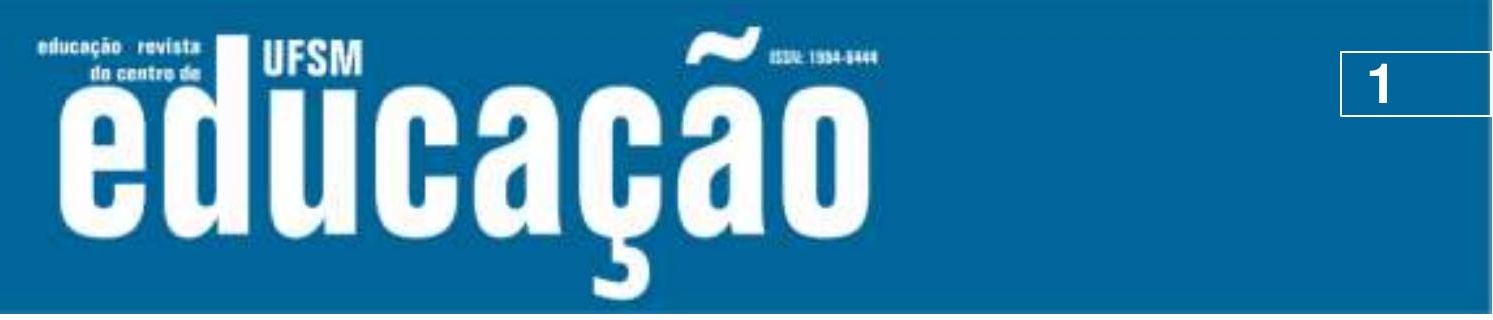

ISSN: 1984-6444 | http://dx.doi.org/10.5902/1984644435076

\title{
Em defesa da arte na pedagogia
}

\author{
In defense of art in pedagogy
}

\section{Francione Oliveira Carvalho}

Professor doutor da Universidade Federal de Juiz de Fora, Juiz de Fora, Minas Gerais, Brasil.

Endereço: Universidade Federal de Juiz de Fora, Faculdade de Educação. Universidade Federal de Juiz de Fora (Campus UFJF), São Pedro. CEP: 36036900. Juiz de Fora, Minas Gerais, Brasil.

E-mail: francioneoliveiracarvalho@gmail.com

Recebido em 06 de outubro de 2018

Aprovado em 30 de outubro de 2018

A obra "Arte e Pedagogia: a margem faz parte do rio", organizado por Sidiney Peterson Ferreira de Lima busca refletir sobre um território ainda pouco explorado na pesquisa acadêmica que é a presença da arte na licenciatura em Pedagogia. Discussão que se fortalece em momento onde novas diretrizes sobre o ensino, e consequentemente, sobre a formação docente, se impõe na Educação Infantil e Ensino Fundamental a partir da Base Nacional Comum Curricular, promulgada no ano de 2017. Afinal, a maior parte dos docentes que lecionam Arte nos anos iniciais da escolarização são oriundos dos diversos cursos de Pedagogia espalhados pelo Brasil. Dessa forma, é fundamental que se investigue e se reflita sobre a maneira como estes cursos operacionalizam, selecionam e constroem conhecimentos sobre arte em seus currículos, e como eles impactam na formação e na atuação profissional de seus egressos.

Para refletir sobre estes, e, outros temas que perpassam a licenciatura em Pedagogia o organizador selecionou quatorze textos escritos por autores de localidades e experiências diversas. A obra tem a apresentação de Analice Dutra Pillar. Muitos textos são escritos por mais de um autor, e revelam o desejo do organizador de promover uma polifonia de vozes, ideias e pontos de vistas. Ao mesmo tempo em que enriqueceu a obra, esta escolha fez com que alguns textos inseridos 


\section{-

ISSN: 1984-6444 | http://dx.doi.org/10.5902/1984644435076

políticas públicas, da interculturalidade e da dimensão política, estética e filosófica inerente ao processo educativo. Há uma grande lacuna na literatura acadêmica relacionada ao tema, o que revela a urgência de mais produções que discutam a importância da arte na licenciatura em Pedagogia.

\section{Referências}

Lima, Sidiney Peterson Ferreira de (org.). Arte e Pedagogia: a margem faz parte do rio. São Paulo: Porto de Idéias, 2017. 278 p.

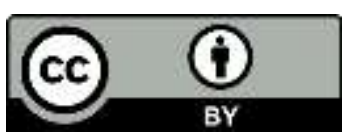

This work is licensed under a Creative Commons Attribution 4.0 International (CC BY 4.0). 